\title{
Korozja połączenia spawanego wykonanego na stali austenitycznej X2CrNi18-9 wywołana występowaniem fazy sigma
}

\author{
Corrosion of weldment made on austenitic steel X2CrNi18-9 \\ caused by sigma phase
}

\section{Streszczenie}

W pracy przedstawiono wyniki badań przeprowadzonych w celu ustalenia przyczyny wystąpienia korozji elementu wykonanego ze stali austenitycznej gatunku X2CrNi18-9. Korozję obserwowano w szczególności w obszarach występowania złączy spawanych. Stwierdzono, że przyczyną powstania korozji była obecność fazy sigma wydzielonej podczas spawania badanych elementów konstrukcyjnych. Stwierdzono, że austenit wykazuje anodowy charakter w stosunku do fazy sigma, co prowadzi do inicjacji wżerów korozyjnych w wyniku powstającego efektu galwanicznego i dalszego rozwoju korozji.

Słowa kluczowe: stal austenityczna; połączenia spawane; X2CrNi18-9; 304L; faza sigma; korozja

\begin{abstract}
The paper presents results of the research performed in order to determine causes of corrosion of the part made of austenitic steel of the X2CrNi18-9 grade. In particular the corrosion was observed in the areas of welded joints. It has been found that the cause of the corrosion was presence of the sigma phase precipitated during welding of the tested structural components. Also, it has been found that austenite shows the anodic character in relation to the sigma phase, which led to initiation of corrosion pits, as a result of the galvanic effect created, and further development of the corrosion.
\end{abstract}

Keywords: austenitic steel; weldment; X2CrNi18-9; 304L; sigma phase; corrosion

\section{Wprowadzenie}

Występująca w układzie Fe-Cr faza $\sigma$ należy do faz międzymetalicznych o sieci tetragonalnej gęsto upakowanej (tcp). Cechuje się dużą twardością i kruchością w temperaturze pokojowej, co przyczynia się do obniżenia właściwości wytrzymałościowych i plastycznych materiałów konstrukcyjnych. Po raz pierwszy została zaobserwowana w stalach austenitycznych w 1966 roku [1]. Występuje przy zawartości żelaza w zakresie od ok. 42 do $50 \%$ at. chromu i jest stabilna w temperaturze niższej od $\mathrm{T}=820^{\circ} \mathrm{C}$ (rys. 1). Wydzielanie bogatej w chrom fazy $\sigma$ prowadzi do obniżania w jej otoczeniu zawartości tego pierwiastka. Głównie z tym wiąże się spadek odporności korozyjnej stali austenitycznych zawierających w mikrostrukturze tę fazę [1].

Krystalizacja fazy $\sigma$ może zachodzić bezpośrednio z austenitu, wymaga to jednak długiego czasu ekspozycji w podwyższonej temperaturze. $Z$ tego względu wydzielenia tego typu spotykane są w materiałach konstrukcyjnych pracujących

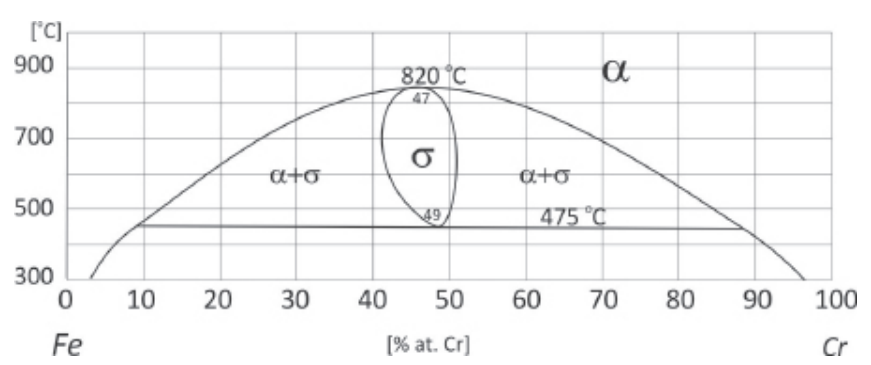

Rys. 1. Fragment wykresu równowagi fazowej układu $\mathrm{Fe}-\mathrm{Cr}$ Fig. 1. Fragment of phase balance diagram of Fe-Cr system

przez dłuższy okres w podwyższonych temperaturach. Dużo łatwiejsze jest zarodkowanie fazy $\sigma$ na granicach międzyfazowych $\delta / y$ lub bezpośrednio z ferrytu $\delta$, który jest bogatszy $w$ chrom niż austenit $[1 \div 3]$ (rys. 2). Ferryt $\delta$ może ulegać całkowitemu rozpadowi lub tylko częściowemu, co wskutek reakcji $(\delta \rightarrow \gamma+\sigma)$ prowadzi do powstania eutektoidu $[4,5]$.

Dr inż. Marzena Lachowicz - Politechnika Wrocławska; mgr inż. Dominika Nowak; dr inż. Maciej Lachowicz - Politechnika Wrocławska; Machinefish Materials \& Technologies Sp. z o.o. Sp. k.

Autor korespondencyjny/Corresponding author: marzena.lachowicz@pwr.edu.pl 


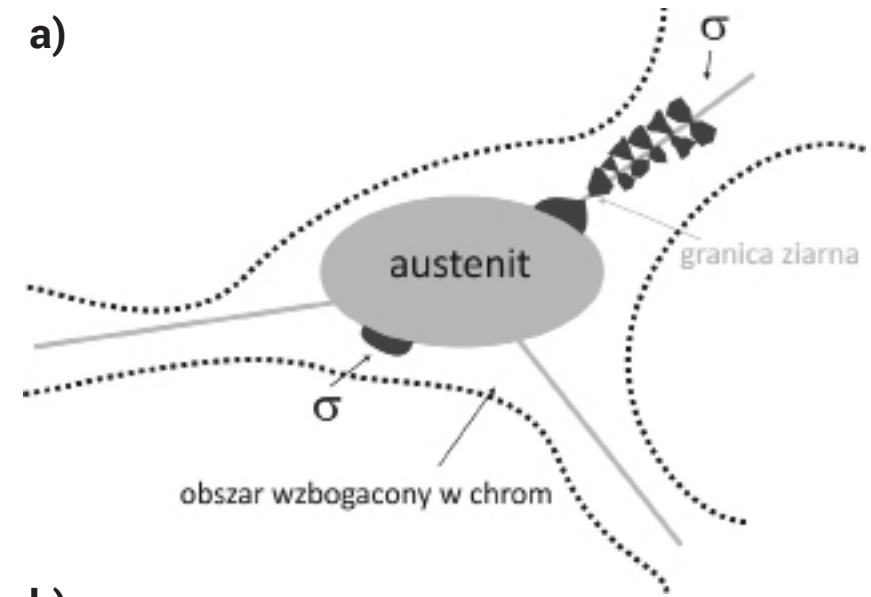

b)

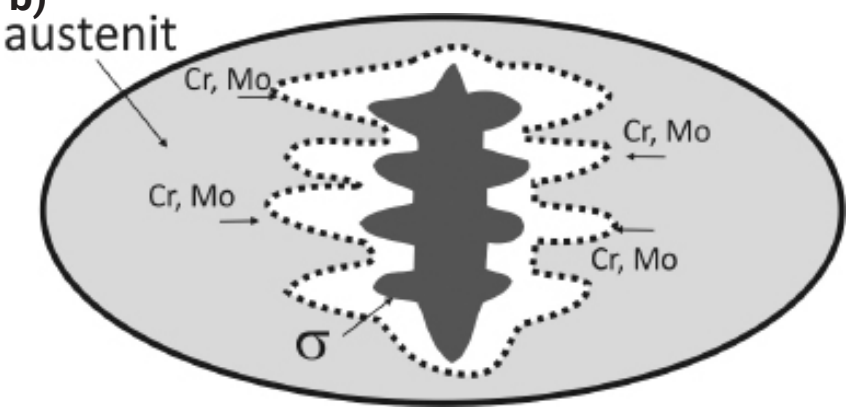

Rys. 2. Mechanizmy wydzielania fazy sigma w stalach austenitycznych: a) bezpośrednio z fazy $y$ i na granicy międzyfazowej $\delta / \gamma$, b) z fazy $\delta$. Na podstawie $[1,2]$

Fig. 2. Mechanisms of sigma phase separation in austenitic steels: a) directly from the $Y$ phase and on the $\delta / \gamma$ interface, b) from the $\delta$ phase. Based on $[1,2]$

Powstawanie fazy $\sigma$ może towarzyszyć różnym technologiom związanym z wytwarzaniem czy łączeniem części maszyn i urządzeń wykonanych ze stali austenitycznych, a im wyższa zawartość chromu w stopie, tym większa tendencja do jej wydzielania [1]. Niebezpieczeństwo wydzielania się tej fazy podczas spawania zwiększa się wraz $z$ rosnącą zawartością ferrytu $\delta \mathrm{w}$ mikrostrukturze stali austenitycznej [5]. Sprzyja temu również segregacja składu chemicznego powstająca podczas spawania, która powoduje, że faza $\delta$ znajdująca się w pierwszych ściegach spoiny może ulegać przemianie $w$ fazę $\sigma \mathrm{w}$ wyniku jej nagrzewania przez kolejne ściegi $[5,6]$.

\section{Materiał i metodyka}

Materiał do badań stanowiła pokrywa komory pompowej wykonana ze stali gatunku X2CrNi18-9 (1.4307) zgodnie z PN-EN 10088-1, która uległa przedwczesnemu zużyciu w wyniku powstania korozji po roku eksploatacji komory. Jej odpowiednikiem według norm AISI jest gatunek 304L. Skład chemiczny stali został potwierdzony z wykorzystaniem metody optycznej spektrometrii emisyjnej (GDOES) firmy LECO GDS500A. Badania makroskopowe wykonano z zastosowaniem mikroskopu stereoskopowego Leica M205 C, natomiast mikroskopowe z wykorzystaniem mikroskopów Leica DM 6000 M oraz Phenom World ProX.

Nie jest znana metoda i parametry spawania badanej pokrywy. Element narażony był na ciągłe oddziaływanie roztworu korozyjnego zawierającego jony chlorkowe, których stężenie czasowo dochodziło do $500 \mathrm{mg} / \mathrm{dm}^{3}$, a pH zawierało się w zakresie od 6.2 do 7.6. Pokrywa była również narażona na czasowe działanie roztworów podchlorynu sodu i kwasu siarkowego.

\section{Badania własne}

\section{Badania mikrostruktury materiału rodzimego} i połączeń spawanych

Podczas badań makroskopowych badanego elementu stwierdzono występowanie licznych lokalnych zniszczeń spowodowanych procesami korozyjnymi. Przejawiało się to powstaniem przebarwień oraz brunatnych produktów korozji na powierzchni pokrywy, występujących w obszarach występowania złączy spawanych, a także obecnością wżerów korozyjnych. Widok ogólny przykładowej spoiny wykonanej na badanym elemencie pokazano na rysunku 3. Poza obszarami połączeń spawanych nie obserwowano widocznych makroskopowo zmian korozyjnych badanego elementu.

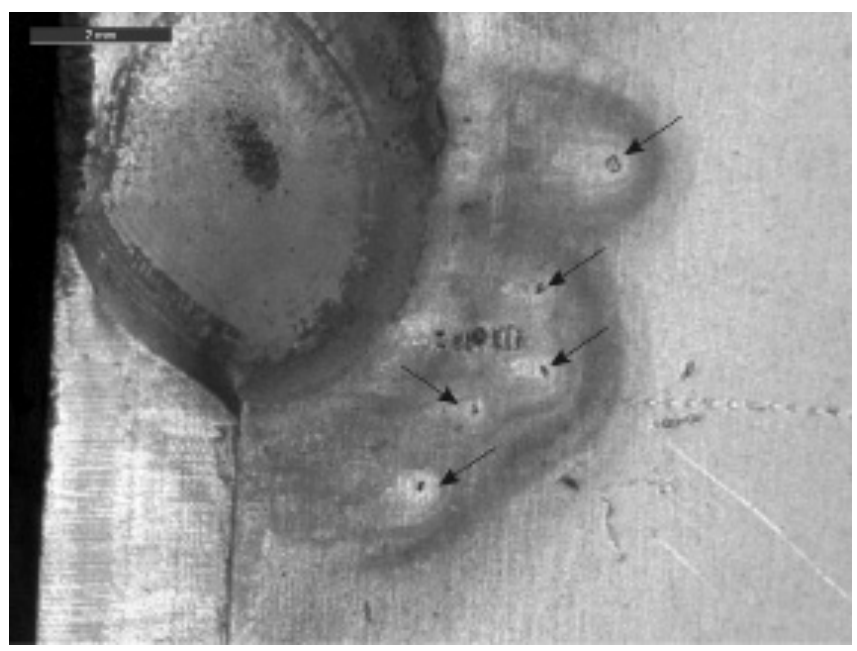

Rys. 3. Obraz stereoskopowy połączenia spawanego. Widoczne utlenienie powierzchni wokół spoiny objawiające się powstaniem przebarwień korozyjnych oraz ognisk korozji wżerowej (zaznaczone strzałkami)

Fig. 3. Stereoscopic image of a welded joint. Visible oxidation of the surface around the weld revealing the formation of corrosive stains and pitting corrosion (indicated by arrows)

Badany element charakteryzował się występowaniem mikrostruktury austenitycznej ze znaczną ilością ferrytu $\delta$ ułożonego $w$ formie pasm zgodnie z kierunkiem przeróbki plastycznej (rys. 4). W obszarze spoiny stwierdzono mikrostrukturę dendrytyczną stali austenitycznej z licznymi wydzieleniami faz występujących w obszarach międzydendrytycznych (rys 5).

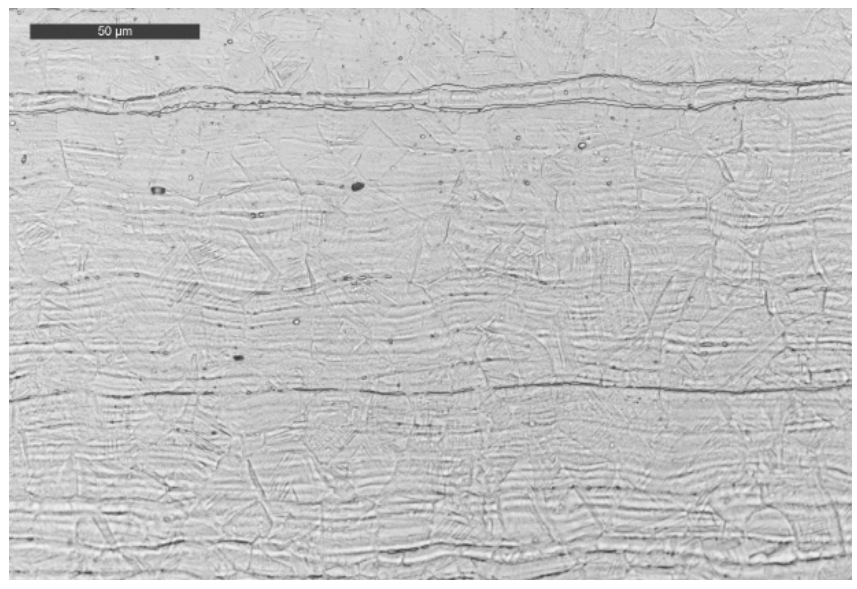

Rys. 4. Mikrostruktura materiału rodzimego. Widoczny austenit z ciągłymi wydzieleniami ferrytu delta ułożonego w formie pasm. Stan trawiony. Mikroskopia świetlna

Fig. 4. Microstructure of native material. Visible austenite with continuous delta ferrite strips arranged in strips. State etched. Light microscopy 


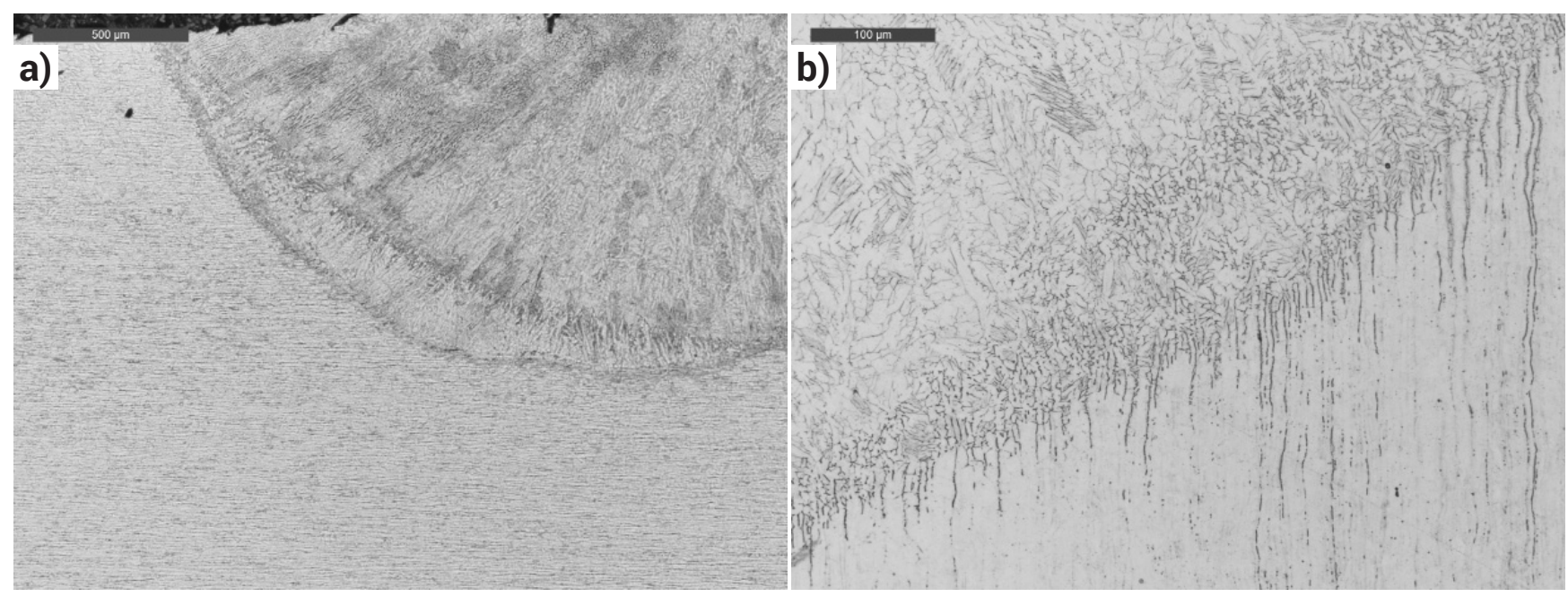

Rys. 5. a) Makrostruktura, b) mikrostruktura połączenia spawanego. W obszarze spoiny widoczna mikrostruktura dendrytyczna z wydzieleniami faz występującymi w obszarach międzydendrytycznych austenitu. Stan trawiony. Mikroskopia świetlna

Fig. 5. a) Macrostructure, b) microstructure of welded joints. In the weld area visible dendritic microstructure with phase separation occurring in the interdendritic austenite. State etched. Light microscopy

W celu potwierdzenia występowania w mikrostrukturze fazy $\sigma$ badany materiał wytrawiono zgodnie $z$ metodą A normy ASTM 923, która powoduje barwne zróżnicowanie pasm ferrytu $\delta$ oraz wydzieleń fazy $\sigma$. Potwierdziło to obecność fazy $\sigma \mathrm{w}$ mikrostrukturze połączeń spawanych, której wydzielanie następowało w obszarach fazy $\delta$. Nie stwierdzono jej obecności w materiale rodzimym, a jedynie występowanie pasm ferrytu $\delta$. W strefie wpływu ciepła obserwowano jednocześnie występowanie obu faz, przy czym ilość fazy $\sigma$ malała wraz z oddaleniem się od obszaru spoiny (rys. 6, 7).

Nie jest znana technologia wykonania badanych połączeń spawanych, można jednak przypuszczać, że podczas spawania zastosowano wysokochromowe stopiwo, które zwiększyło tendencję do wydzielania się fazy sigma w wyniku zwiększonej zawartości chromu.

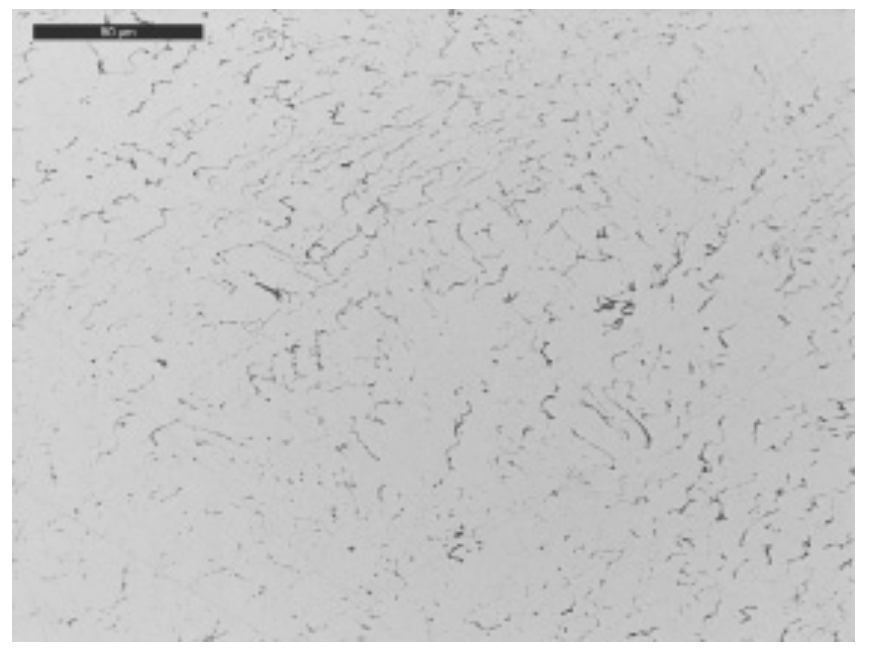

Rys. 6. Mikrostruktura w obszarze spoiny. Widoczne wydzielenia fazy $\sigma$ występujące $w$ obszarach międzydendrytycznych austenitu. Trawiono zgodnie z metodą A normy ASTM 923. Mikroskopia świetlna

Fig. 6. Microstructure in the weld area. Visible phase separation $\sigma$ occurring in the interdendritic areas of austenite. It was etched according to method A of ASTM 923. Light microscopy

\section{Badania mikroskopowe zmian korozyjnych}

Przeprowadzono badania mikroskopowe powierzchni materiału rodzimego eksponowanego na oddziaływanie czynnika korozyjnego. Pomimo niewidocznych makroskopowo zmian korozyjnych, obserwacje mikroskopowe SEM

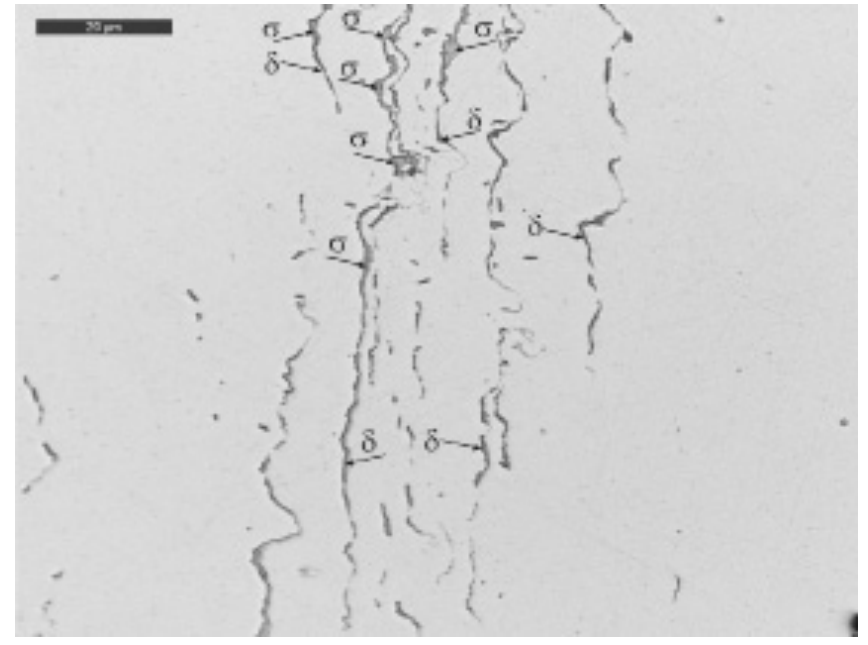

Rys. 7. Mikrostruktura w obszarze SWC. Widoczne wydzielenia fazy $\sigma$ oraz $\delta$ ułożone pasmowo wzdłuż kierunku przeróbki plastycznej. Trawiono zgodnie z metodą A normy ASTM 923. Mikroskopia świetlna Fig. 7. Microstructure in SWC area. Visible phase separation $\sigma$ and $\delta$ staggered along the plastic working direction. It was etched according to method A of ASTM 923. Light microscopy

ujawniły roztwarzanie granic ziaren austenitu, a także obszarów występowania pasm ferrytu $\delta$ (rys. 8). Identyfikację fazy $\delta$ (pkt. 1, rys 8) potwierdza również obecność w jej składzie chemicznym manganu, o większej rozpuszczalności w ferrycie niż w austenicie (pkt. 2, rys. 8), a także wyższa niż w austenicie zawartość chromu. Mangan nie jest obecny również w składzie chemicznym fazy $\sigma$. Roztwarzanie wydzieleń ferrytu $\delta$ w obecności austenitu wskazuje na jego anodowy charakter w eksploatacyjnym środowisku korozyjnym.

Obraz mikroskopowy powierzchni próbki reprezentujący obszar przetopu materiału po stronie spoiny pokrytej produktami korozji przedstawiono na rysunku 9. Stwierdzono roztwarzanie fazy $\gamma$, występujące na całej powierzchni i ujawniające jej dendrytyczny charakter. W strefie wpływu ciepła stwierdzono występowanie lokalnej korozji wżerowej w obszarach istnienia dendrytycznej fazy $\sigma$ (rys. 10). Przeprowadzone badania mikroskopowe wskazują, że austenit wykazuje anodowy charakter w stosunku do fazy sigma, co prowadzi do powstawania mikroogniw korozyjnych pomiędzy austenitem i $\sigma$, a w konsekwencji do korozji austenitu. Sprzyja temu zubożenie w chrom obszarów przyległych do fazy $\sigma$. 
Punkt 1

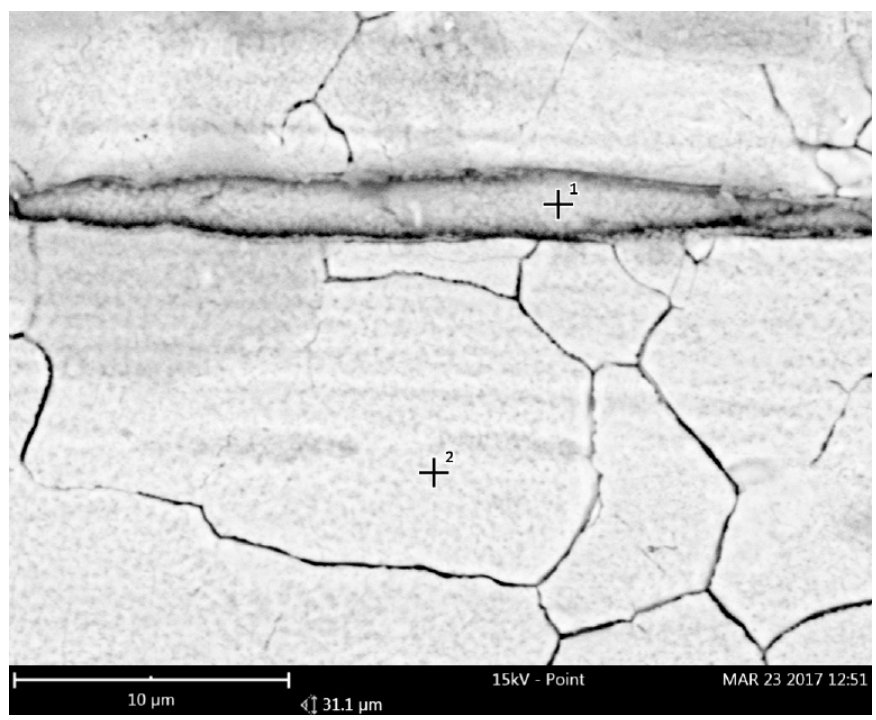

\begin{tabular}{|c|c|c|}
\hline $\begin{array}{c}\text { Symbol } \\
\text { pierwiastka }\end{array}$ & \% at. & \% wag. \\
\hline $\mathrm{Fe}$ & 59,03 & 66,39 \\
\hline $\mathrm{Cr}$ & 24,85 & 26,02 \\
\hline 0 & 13,05 & 4,21 \\
\hline $\mathrm{Mn}$ & 3,07 & 3,39 \\
\hline
\end{tabular}

Punkt 2

\begin{tabular}{|c|c|c|}
\hline $\begin{array}{c}\text { Symbol } \\
\text { pierwiastka }\end{array}$ & \% at. & \% wag. \\
\hline $\mathrm{Fe}$ & 53,23 & 65,77 \\
\hline $\mathrm{Cr}$ & 14,35 & 16,51 \\
\hline $\mathrm{O}$ & 25,81 & 9,14 \\
\hline $\mathrm{Ni}$ & 6,61 & 8,58 \\
\hline
\end{tabular}

Rys. 8. Zmiany korozyjne występujące na powierzchni materiału rodzimego. Widoczne roztwarzanie granic ziaren oraz ferrytu delta. Punktami 1 i 2 zaznaczono miejsca wykonania mikroanalizy składu chemicznego. SEM

Fig. 8. Corrosive changes occurring on the surface of native material. Visible breaking of grain boundaries and delta ferrite. Points 1 and 2 indicate where the microanalysis of the chemical composition is located. SEM
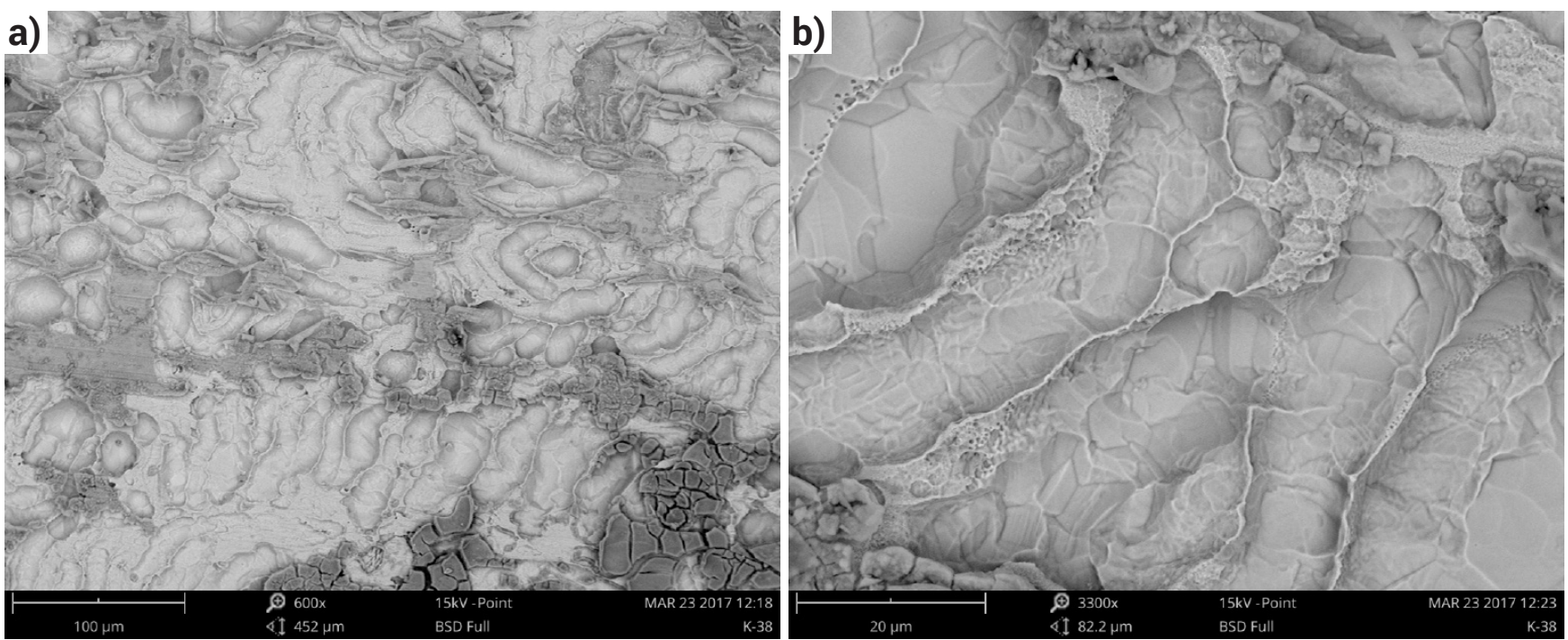

Rys. 9. Strefa przetopienia spoiny punktowej. Widoczne roztwarzanie dendrytycznych wydzieleń austenitu i produkty korozji pokrywające powierzchnię. SEM

Fig. 9. Remelting zone of the spot weld. Visible cracking of dendritic austenite precipitates and corrosion products covering the surface.SEM

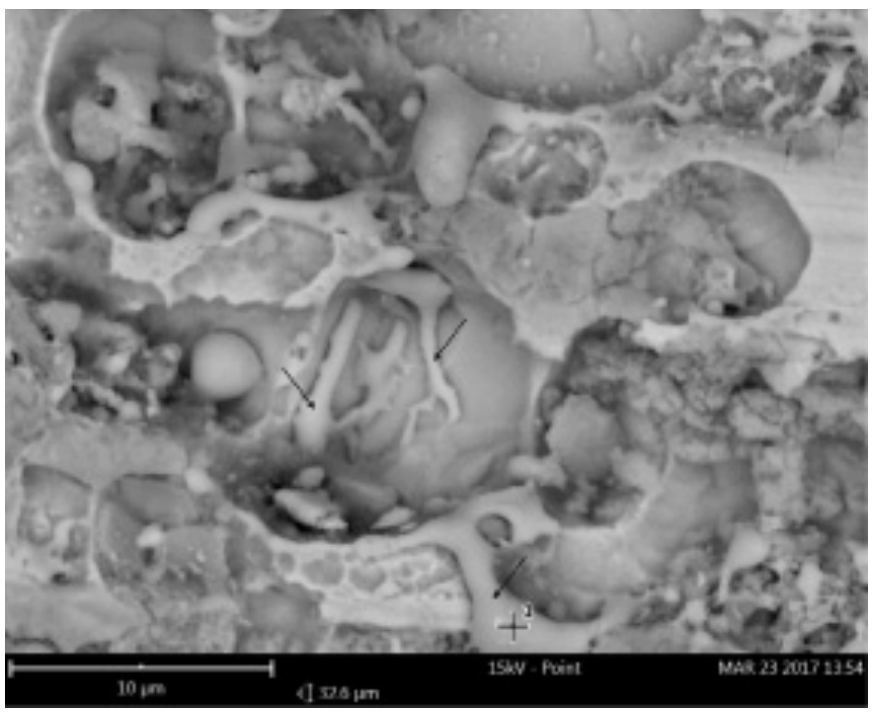

\section{Punkt 1}

\begin{tabular}{|c|c|c|}
\hline $\begin{array}{c}\text { Symbol } \\
\text { pierwiastka }\end{array}$ & \% at. & \% wag. \\
\hline $\mathrm{Fe}$ & 22,11 & 39,77 \\
\hline $\mathrm{O}$ & 60,55 & 31,20 \\
\hline $\mathrm{Cr}$ & 17,34 & 29,03 \\
\hline
\end{tabular}

Rys. 10. Strefa wpływu ciepła. Widoczna korozja wżerowa austenitu powstała wokół dendrytycznych wydzieleń fazy $\sigma$ (zaznaczone strzałkami). W punkcie 1 zaznaczono miejsce wykonania mikroanalizy składu chemicznego. SEM

Fig. 10. Zone of heat impact. Visible pitting corrosion of austenite was formed around the dendritic phases of $\sigma$ (marked with arrows). The microanalysis of chemical composition is indicated in point 1 . SEM 


\section{Podsumowanie}

Spawanie stali austenitycznej zawierającej wydzielenia ferrytu $\delta$ może prowadzić do powstawania fazy $\sigma$ w obszarze przetopienia i strefie wpływu ciepła. Prowadzi to nie tylko do obniżenia właściwości mechanicznych łączonych elementów konstrukcyjnych, ale również sprzyja wystąpieniu silnej korozji elektrochemicznej, szczególnie w roztworach zawierających jony chlorków. W stalach austenitycznych zawierających ferryt delta i fazę sigma, najwyższy potencjał elektrochemiczny wykazuje faza sigma. Anodowy charakter austenitu w stosunku do fazy $\sigma$, prowadzi do inicjacji procesów korozyjnych w jej otoczeniu. Im wyższa zawartość fazy $\sigma \mathrm{w}$ mikrostrukturze stali, tym bardziej rozbudowana powierzchnia ulegająca procesom korozyjnym. W obszarze przetopienia, gdzie obserwowano wydzielanie się dużej ilości tej fazy, korozja dotyczyła całej powierzchni elementu. W SWC, gdzie obserwowano mniejszą zawartość fazy $\sigma$, stwierdzono występowanie lokalnej korozji wżerowej, zainicjowanej w miejscach jej istnienia. Ze względu na agresywne środowisko, korozja objęła również materiał rodzimy, jednak miała ona bardziej powierzchowny charakter i nie była obserwowalna makroskopowo.

Wyższa zawartość chromu występująca w ferrycie $\delta$ sprzyja tworzeniu fazy $\sigma$. Z tego względu stosowanie stopiw wysokochromowych będzie dodatkowo zwiększało tendencję do wydzielania się tej fazy. Sprzyja jej również oddziaływanie złożonych cykli cieplnych podczas spawania. Niemniej jednak wydzielanie się fazy $\sigma$ podczas spawania pozwoli uniknąć dokładna kontrola procesu spawania ograniczająca możliwość nadmiernego przegrzania materiału. Natomiast usunięcie wydzielonej już fazy $\sigma$, możliwe jest wyłącznie na drodze obróbki cieplnej połączenia spawanego (przesycania).

\section{Literatura}

[1] C.-C. Hsieh, W. Wu: Overview of Intermetallic Sigma (б) Phase Precipitation in Stainless steels, vol. 2012, ISRN Metallurgy, pp. 2-17, 2012.

[2] Y. S. Na, N. K. Park, R. C. Reed: Sigma morphology and precipitation mechanism in Udimet 720Li, vol. 43, Scripta Materiala, pp. 585-590, 2000

[3] R. L. Plaut, C. Herrera, D. M. Escriba, P. R. Rios, A. F. Padilha: A short review on wrought austenitic stainless steels at high temperatures: processing, microstructure, properties and performance; vol. 10, nr 4, pp. 453-460, 2007.
[4] D. M. E. Villanueva, F. C. P. Junior, R. L. Plaut, A. F. Padilha: Comperative study on sigma phase precipitation of three types of stainless steels: austenitic, superferritic and duplex; vol. 22, nr 9, pp. 1098-1104, 2006.

[5] E. Tasak, A. Ziewiec, M. Ciesielka: Pękanie połączeń spawanych eksploatowanych w podwyższonych temperaturach, vol. 7, s. 7-9, 2007.

[6] E. Tasak: Metalurgia spawania, Kraków, 2008. 